\title{
ОСОБЕННОСТИ МИГРАЦИИ ТЯЖЕЛЫХ МЕТАЛЛОВ В СИСТЕМЕ «ПРИДОННАЯ ВОДА - ПОРОВАЯ ВОДА - ПОВЕРХНОСТНЫЙ СЛОЙ ДОННЫХ ОТЛОЖЕНИЙ ПРИБРЕЖНОЙ ЗОНЫ ВОСТОЧНОЙ ЧАСТИ ФИНСКОГО ЗАЛИВА В ВЕСЕННЕ-ЛЕТНИЙ ПЕРИОД
}

\author{
Кудрявцева Валентина Александровна', \\ valenkud@yandex.ru
}

\author{
Шигаева Татьяна Дмитриевна ${ }^{1}$, \\ t.sh54@mail.ru
}

Панкратова Надежда Максимовна², nadja.pan@gmail.com
1 Санкт-Петербургский научно-исследовательский центр экологической безопасности Российской академии наук - обособленное структурное подразделение ФГБУН «Санкт-Петербургский Федеральный исследовательский центр Российской академии наук», Россия, 197110, г. Санкт-Петербург, ул. Корпусная, 18.
2 Sentec $A G$,
Швейцария, 4106, г. Тервиль, Рингштрасе, 39.

\begin{abstract}
Актуальность исследования обусловлена необходимостью изучения вторичного загрязнения водной среды металлами в весенне-летнее время, когда активизируются разнообразные биогеохимические процессы, влияющие на изменение физикохимического состояния поверхностного слоя донных отложений.

Цель: изучение закономерностей образования и миграции растворимых форм металлов в системе «донные отложения - поровая вода - придонная вода» в весенне-летнее время в прибрежной зоне восточной части Финского залива.

Объекты: пробы поверхностного слоя донных отложений, поровой и придонной воды пяти станций прибрежной зоны восточной части Финского залива.

Методы: потенциометрический метод определения $\mathrm{pH}$ и Eh в донных отложениях и придонной воде. Валовые концентрации $\mathrm{Fe}, \mathrm{Zn}, \mathrm{Cd}, \mathrm{Pb}, \mathrm{Cu}$ в донных отложениях определяли методом масс-спектрометрии с индуктивно-связанной плазмой (ICP-MS). Концентрации растворенных фоорм металлов ( $\mathrm{Fe}, \mathrm{Cu}, \mathrm{Cd}, \mathrm{Zn}, \mathrm{Pb}$ ) в поровой, придонной водах определяли методом масс-спектрометрии с индуктивно-связанной плазмой на приборе «Agilent 7700х» (фирма «Agilent Technologies»).

Результаты. Установлены закономерности образования и миграции растворимых фрорм металлов на границе «донные отложения - вода» в прибрежной зоне восточной части Финского залива в зависимости от изменений температуры, кислородного режима в придонных водах и окислительно-восстановительных процессов, формирующихся в поверхностном слое донных отложений. Показано, что в конце весеннего сезона в донных отложениях восточной части Финского залива устанавливаются восстановительные условия, способствующие восстановлению гидроксидов железа, накопившихся на дне. В результате возникает поток растворенных форм $\mathrm{Fe}, \mathrm{Cu}, \mathrm{Zn}, \mathrm{Cd}, \mathrm{Pb}$ в поровые и придонные слои воды. В июле загрязненность поровых и придонных вод всеми изученными металлами снижается.
\end{abstract}

\section{Ключевые слова:}

Донные отложения, поровые воды, придонные воды, тяжелые металлы, Финский залив.

\section{Введение}

Быстрые темпы индустриализации и городского развития приводят к существенным загрязнениям окружающей среды потенциально токсичными элементами, которые стали угрозой для здоровья человека и пищевых цепей. Различные виды антропогенной деятельности оказывают большое влияние на экологию водных объектов во многих частях мира, и этот процесс будет только усугубляться. Особенно следует отметить вклад изменения климата в ухудшение экологической обстановки в мире $[1,2]$. Глобальное повышение температуры и изменение структуры и состояния донных отложений вызывают серьезные экологические изменения в водных экосистемах [3, 4]. Кроме того, повышенная температура может привести к изменению биодоступности токсикантов, накопленных в прошлом, и повысить вероятность их поглощения водными организмами. Последние, в свою очередь, снижают первичную продуктивность и изменяют микробное разложение, создавая таким образом еще один ключевой контур обратной связи между продуктивностью, изменением климата и загрязнителями окружающей среды. Потепление может также усиливать эвтрофикацию и осаждение загрязнителей в органических отложениях [3].

Загрязнение водных экосистем тяжелыми металлами (ТМ) вызывает серьезную озабоченность в связи с их токсичностью, биоаккумуляцией, латентностью и вытекающими из этого потенциальными экологическими рисками [5]. ТМ поступают в водоемы различными путями и от многих источников, включая естественное выветривание горных пород, атмосферные осадки, эрозию почв, поверхностные стоки, различные виды антропогенной деятельности, и могут переноситься и откладываться в донных отложениях (ДО) временно или постоянно [6]. ДО часто служат эффек- 
тивными накопителями загрязняющих веществ и благодаря этому могут обеспечить достоверную картину изменения качества воды с течением времени [7].

Исследование загрязнения донных осадков тяжелыми металлами считается одним из наиболее эффективных способов оценки экологического состояния водного объекта, так как дает объективную информацию относительно уровня загрязнения водоема. При тех или иных изменениях водной среды тяжелые металлы из донных отложений через ряд физических, химических и биологических процессов снова попадают в воду. Помимо «исполнения» функций «поглотителя» и «источника» ТМ, состояние донных отложений тесно связано с благополучием и устойчивостью всей водной экосистемы. Поскольку химическое поведение и экологические эффекты ТМ в водных экосистемах сложны, исследования их поведения в ДО в последние годы стали «горячей» темой. Изменение окислительно-восстановительных условий в ДО для содержащихся в них ТМ имеет два основных следствия: во-первых, происходит изменение валентности металлов, и, во-вторых, изменяются их формы нахождения. Верхний (0-10 см) слой ДО является наиболее активным, непосредственно участвующим в обменных процессах с поровыми и придонными водами [8]. В зависимости от гидрологического сезона в нем могут преобладать либо окислительные, либо восстановительные условия, которые, в свою очередь, определяют формы нахождения ТМ, а следовательно, и их биодоступность для микроорганизмов. Окислительные условия преобладают в зимне-весеннее время года, когда понижение температуры воды способствует повышению содержания растворенного кислорода и замедлению биохимических процессов окисления органического вещества. В летне-осеннее время происходит понижение концентрации растворенного кислорода за счет повышения температуры воды и его интенсивного расходования на биохимические процессы. В результате в поверхностном слое ДО могут возникать восстановительные условия. Следствием этого являются сезонные изменения содержания ТМ в ДО.

Проблема загрязнения ДО потенциально опасными для экосистемы веществами является чрезвычайно актуальной для Финского залива. Активные дноуглубительные работы, строительство портов приводят к вторичному загрязнению акватории в результате взмучивания ДО. В работе Ю. Поляк др. [9] установлено, что в прибрежной зоне Финского залива, в районе Приморска, порта Бронка и Большой Ижоры, значения окислительно-восстановительного потенциала (Eh) ДО находятся в области отрицательных значений -100 мВ (относительно насыщенного хлорсеребряного электрода), что соответствует границе перехода от окисленной к восстановленной зоне. Такие условия способствуют выходу соединений металлов из ДО и загрязнению воды. В районе Графской бухты и Систо-Палкино Eh находится на уровне $-250 \mathrm{mB}$, т. е. среда еще более восстановленная, и, следовательно, процессы выхода металлов могут усиливаться [9]. Основной причиной снижения окислительно- восстановительного потенциала на этих станциях являются макроводоросли, биомасса которых на станциях с отрицательным значением Eh значительно выше, чем на других станциях. В местах скопления водорослей формируются водорослевые маты, из разлагающейся биомассы которых в воду и придонные слои поступают металлы. Кроме того, дефицит кислорода под водорослевыми матами способствует снижению окислительно-восстановительного потенциала и переходу металлов в подвижную форму, что приводит к дополнительной антропогенной нагрузке на прибрежную экосистему [10]. Данные процессы могут вызвать повышенное загрязнение воды и донных отложений, учитывая масштабный характер, который приобретают «цветения» водорослей в последние годы в условиях глобального потепления климата.

Климатические изменения и, соответственно, вероятность вторичного загрязнения водной среды металлами в летнее время, когда активизируются разнообразные биогеохимические процессы в условиях повышенных температур, обуславливают актуальность исследований в этом направлении. Полученные результаты в перспективе могут найти применение при разработке геохимических моделей трансформации и миграции металлов в водных объектах, а также представляют определенный интерес для госструктур по охране окружающей среды и обеспечению экологической безопасности.

Целью настоящей работы является изучение закономерностей образования и миграции растворимых форм металлов в системе «донные отложения - поровые воды - придонные воды» в весенне-летнее время в прибрежной зоне восточной части Финского залива.

\section{Объекты, материалы и методы исследования}

Объектом исследования являлись пробы поверхностного слоя ДО, поровые и придонные воды, отобранные в прибрежной мелководной зоне восточной части Финского залива в мае и июле 2018 и 2019 гг. Известно, что верхний десятисантиметровый слой ДО непосредственно участвует в обменных процессах с поровыми и придонными водами [8]. В настоящем исследовании отбор образцов ДО производился пробоотборником Робур-ИЛ с верхнего поверхностного слоя (0-5 см) ДО на расстоянии приблизительно $10 \mathrm{~m}$ от береговой линии, где глубина достигала $0,5 \mathrm{~m}$. Придонными водами считался слой воды, прилегающий к ДО. Отбор вод осуществлялся горизонтальным батометром Ван-Дорма. Пробы отбирались в местах постоянно закрепленных станций. Обязательным условием пробоотбора было отсутствие волнения в заливе.

На рис. 1 представлены станции, на которых производился забор проб донных отложений и воды. Станции располагались на северном и южном побережьях восточной части залива, в местах, испытывающих непосредственное антропогенное воздействие, в частности, морских портов и терминалов (Ломоносов, Приморск), недалеко от автотрассы (Большая Ижора), а также в местах, не подверженных внешнему антропогенному воздействию (Репино, Дубки). 


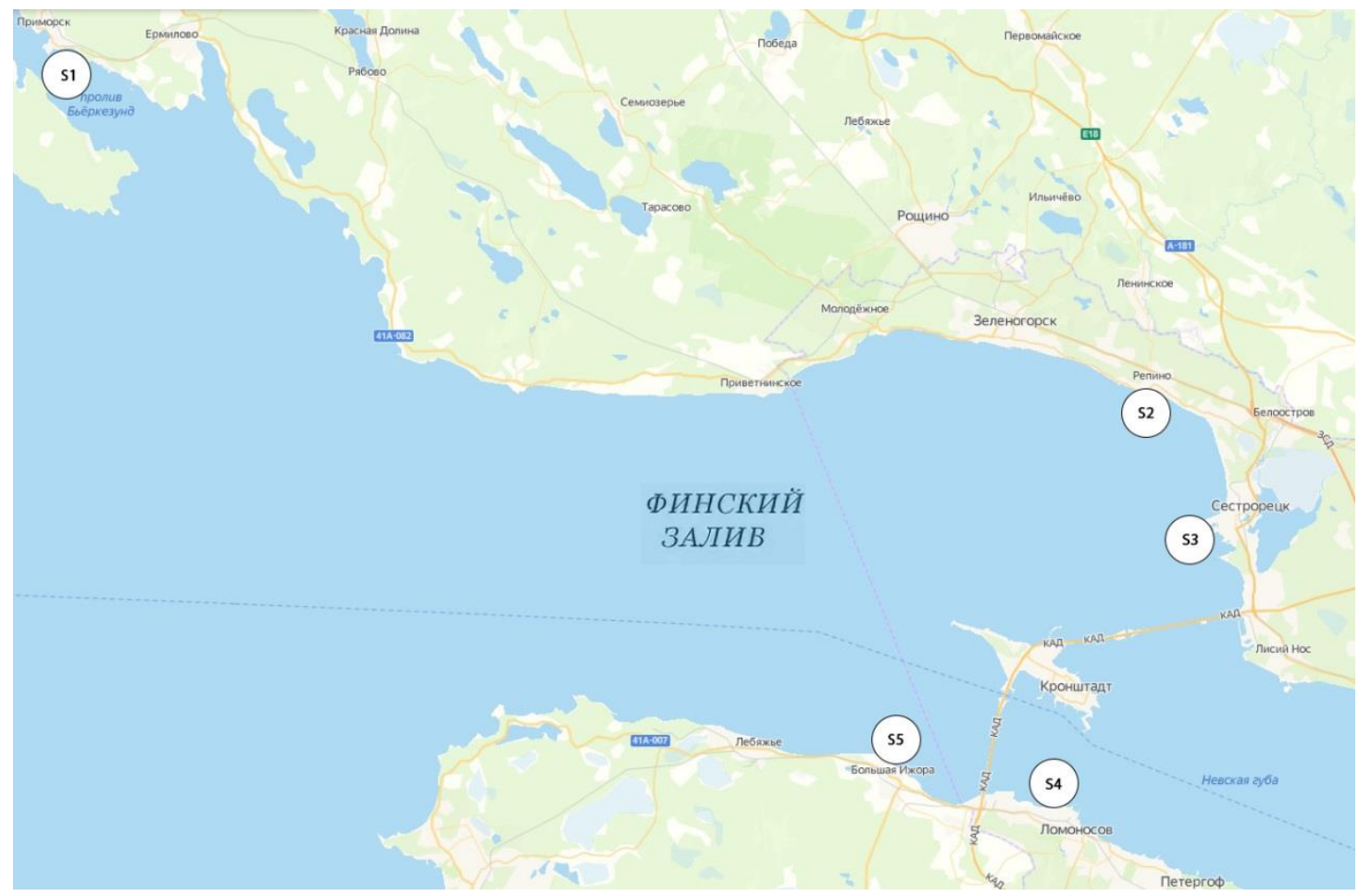

Pис. 1. Расположение точек отбора проб в восточной части Финского залива: Приморск (S1), Репино (S2), Дубки (S3), Ломоносов (S4), Большая Ижора (S5)

Fig. 1. Location of the sampling sites in the eastern Gulf of Finland: Primorsk (S1), Repino (S2), Dubki (S3), Lomonosov (S4), Big Izhora (S5)

Образцы ДО высушивали при температуре $30^{\circ} \mathrm{C}$. Перед анализом общего содержания ТМ пробы донных осадков дополнительно истирали в порошок в агатовой ступке. Для получения поровой воды пробы ДО отстаивали до разделения жидкой и твердой фаз. Поровые воды отделялись от твердой фазы при центрифугировании со скоростью 3000 оборотов в минуту в течение 30 минут. Перед проведением анализов поровой и придонной воды все пробы отфильтровывались через мембранный фильтр 0,45 мкм.

Измерение $\mathrm{pH}$ и Еh проводили с помощью $\mathrm{pH}$ метра $\mathrm{pH} 420$ (фирма «Аквилон»). Измерительными электродами служили комбинированный оксредэлектрод InLab®Redox, состоящий из платинового кольцевого измерительного электрода и хлорсеребряного электрода сравнения, и комбинированный $\mathrm{pH}-$

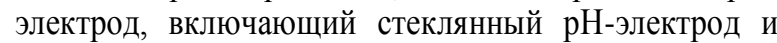
электрод сравнения. Валовые концентрации ТM (Fe, $\mathrm{Zn}, \mathrm{Cd}, \mathrm{Pb}, \mathrm{Cu})$ определяли методом массспектрометрии $\mathrm{c}$ индуктивно-связанной плазмой
(ICP-MS) на приборе «Agilent 7700x» (фирма «Agilent Technologies»). Концентрации растворенных форм металлов $(\mathrm{Fe}, \mathrm{Cu}, \mathrm{Cd}, \mathrm{Zn}, \mathrm{Pb})$ в поровой и придонной водах также определяли методом масс-спектрометрии с индуктивно-связанной плазмой на приборе «Agilent 7700х» (фирма «Agilent Technologies»).

\section{Результаты и их обсуждение}

В ранее проведенных исследованиях В.А. Кудрявцевой и др. [11] методом лазерной седиментографии был определен гранулометрический состав проб ДО. ДО прибрежной зоны восточной части Финского залива представлены песчаными фракциями с незначительным содержанием алевритовых и глинистых частиц (менее $10 \%$ ). В табл. 1, 2 представлены значения окислительно-восстановительных потенциалов ДО и средние значения валовых концентраций $\mathrm{Fe}, \mathrm{Cu}$, $\mathrm{Zn}, \mathrm{Cd}$ и $\mathrm{Pb}$ в поверхностном слое ДО прибрежной зоны северной и южной частей Финского залива в весенний и летний периоды.

Таблица 1. Средние значения \pm стандартное отклонение валовых конщентраций металлов и Еһ в поверхностном слое ДО в весенний период

Table 1. Mean values \pm standard deviation of gross metal concentration and Eh in the surface sediments at the sampling sites in the eastern Gulf of Finland in spring

\begin{tabular}{|c|c|c|c|c|c|c|}
\hline \multirow{2}{*}{$\begin{array}{c}\text { Станция } \\
\text { Site }\end{array}$} & \multirow{2}{*}{$\mathrm{Eh}, \mathrm{MB} / \mathrm{mV}$} & \multicolumn{5}{|c|}{$\begin{array}{c}\text { Концентрации металлов }\left(\mathrm{м \Gamma}^{*} \mathrm{\kappa г}^{-1}\right) \\
\text { Metal content }\left(\mathrm{mg} \cdot \mathrm{kg}^{-1}\right)\end{array}$} \\
\cline { 3 - 7 } & & $\mathrm{Fe}$ & $\mathrm{Cu}$ & $\mathrm{Zn}$ & $\mathrm{Cd}$ & $\mathrm{Pb}$ \\
\hline S1 & -212 & $18400 \pm 2430$ & $10,31 \pm 1,03$ & $36,10 \pm 4,69$ & $0,301 \pm 0,042$ & $23,9 \pm 3,3$ \\
\hline S2 & -142 & $15900 \pm 1644$ & $3,06 \pm 0,28$ & $18,92 \pm 2,08$ & $0,091 \pm 0,013$ & $14,9 \pm 1,9$ \\
\hline S3 & -154 & $14200 \pm 1420$ & $4,68 \pm 0,56$ & $34,91 \pm 4,19$ & $0,230 \pm 0,032$ & $18,5 \pm 2,2$ \\
\hline S4 & -231 & $17100 \pm 2328$ & $4,93 \pm 0,74$ & $18,41 \pm 2,21$ & $0,110 \pm 0,016$ & $14,6 \pm 1,5$ \\
\hline S5 & -216 & $13400 \pm 4702$ & $7,83 \pm 0,94$ & $15,37 \pm 1,69$ & $0,076 \pm 0,011$ & $15,3 \pm 1,8$ \\
\hline
\end{tabular}


Таблица 2. Средние значения \pm стандартное отклонение валовых концентраций металлов и Еһ в поверхностном слое ДО в летний период

Table 2. Mean values \pm standard deviation of gross metal concentration and Eh in the surface sediments at the sampling sites in the eastern Gulf of Finland in summer

\begin{tabular}{|c|c|c|c|c|c|c|}
\hline \multirow{2}{*}{$\begin{array}{c}\text { Станция } \\
\text { Site }\end{array}$} & \multirow{2}{*}{ Eh, мB/mV } & \multicolumn{5}{|c|}{$\begin{array}{c}\text { Концентрации металлов }\left(\mathrm{мг}^{*} \mathrm{\kappa}^{-1}\right) \\
\text { Metal content }\left(\mathrm{mg} \cdot \mathrm{kg}^{-1}\right)\end{array}$} \\
\cline { 3 - 7 } & & $\mathrm{Fe}$ & $\mathrm{Cu}$ & $\mathrm{Zn}$ & $\mathrm{Cd}$ & $\mathrm{Pb}$ \\
\hline S1 & -196 & $19400 \pm 3472$ & $11,21 \pm 1,34$ & $43,30 \pm 5,18$ & $0,211 \pm 0,031$ & $28,7 \pm 3,7$ \\
\hline S2 & -196 & $13700 \pm 1067$ & $3,29 \pm 0,46$ & $18,72 \pm 1,87$ & $0,112 \pm 0,017$ & $17,8 \pm 1,9$ \\
\hline S3 & -16 & $23400 \pm 3276$ & $4,41 \pm 0,53$ & $46,51 \pm 2,92$ & $0,140 \pm 0,019$ & $18,7 \pm 2,2$ \\
\hline S4 & -190 & $19400 \pm 2560$ & $7,10 \pm 0,64$ & $53,11 \pm 6,37$ & $0,310 \pm 0,046$ & $20,6 \pm 2,5$ \\
\hline S5 & -133 & $18400 \pm 2010$ & $3,11 \pm 0,03$ & $21,12 \pm 1,69$ & $0,057 \pm 0,008$ & $18,9 \pm 1,7$ \\
\hline
\end{tabular}

Сравнивая концентрации растворенных форм металлов в ДО, следует отметить, что в весенний период наибольшее содержание соединений ТМ наблюдается в Приморске, в июле месяце, наряду с Приморском, ухудшается ситуация в Ломоносове. Эти две станции подвержены антропогенному воздействию в связи с активно развивающимся морским производством и транспортной инфраструктурой.

На всех станциях при переходе от весеннего сезона к летнему происходит увеличение концентрации железа в ДО. Известно, что восстановительный диагенез в ДО подо льдом может начинаться ранней весной, еще при ледоставе, и продолжаться после таяния льда в апреле-мае с повышением температуры воды, в результате чего происходит восстановление соединений железа и переход их в поровую воду [12]. В нашем случае в мае месяце на всех станциях в ДО сформировалась восстановленная среда, что подтверждается значениями окислительновосстановительного потенциала. Таким образом, при установлении в верхнем слое ДО восстановительных условий гидроксиды железа восстанавливаются до растворенных форм соединений, где железо находится в степени окисления +2 , которые затем посредством диффузии мигрируют в верхние водные слои, вследствие чего может иметь место вторичное загрязнение воды этими катионами. Установлена корреляционная связь между Еh и валовым содержанием железа в поверхностном слое ДО со значением коэффициента корреляции 0,65 (при уровне значимости $0,05, \mathrm{n}=20)$. В летний период смещение Eh в область положительных значений приводит к увеличению содержания нерастворимых соединений железа в ДО, что особенно заметно на станции Дубки.

Сезонная динамика изменения соединений меди, цинка, кадмия свинца в ДО практически не связана с изменением окислительно-восстановительного состояния придонного слоя ДО. Все миграционные процессы в большей или меньшей степени связаны с изменением количества гидроксидов железа, что достоверно подтверждается коэффициентом корреляции со значением 0,70 для цинка, 0,55 для свинца при уровне значимости 0,05 $(\mathrm{n}=20)$. Для меди и кадмия коэффициенты корреляции равны 0,33 и 0,47, соответственно, т. е. выходят за уровень достоверности. Таким образом степень влияния гидроксидов железа на сорбцию соединений цинка и свинца проявляется значительно больше, чем следовало бы ожидать исходя из их массовой доли в составе частиц донных осадков. Это свя- зано со способностью гидроксидов железа покрывать тонким слоем поверхность других частиц твердого осадка, что значительно увеличивает их рабочую сорбционную площадь [13, 14].

В настоящее время изучение содержания ТМ в ДО связывают с миграцией и распределением химических элементов между донными осадками и придонным водным слоем в условиях климатических изменений, происходящих в последние годы [15-17]. Это особенно актуально для оценки вероятности вторичного загрязнения водной среды металлами. С этой целью определены концентрации растворимых форм железа, меди, цинка, кадмия и свинца в поровой и придонной водах в весенний и летний период. Результаты исследований представлены в табл. 3.

Анализ представленных в табл. 3 концентраций растворенных форм металлов показал, что в весенний период более восстановленная среда ДО способствует восстановлению и растворению соединений железа в осадках и переходу их в поровые растворы. Восстановленная среда в ДО сохранялась в течение всего времени натурных исследований, тем не менее в летний период значения Eh сдвинулись в положительную сторону, в связи с чем процесс диагенетического растворения гидроксидов железа в июле замедлился и одновременно с этим наблюдалось активное накопление $\mathrm{Fe}^{2+}$ в придонных водах. Для понимания процесса нами был изучен уровень растворенного кислорода в придонном водном слое. В работе Т.Д. Шигаевой и др. [18] отмечено, что при формировании анаэробных условий на границе раздела «донные отложения - вода» преобладают процессы восстановления, что является одним из важнейших факторов повышения миграционной подвижности химических веществ в ДО и их перехода в придонную воду. В июле-августе в прибрежной зоне Финского залива в основном преобладает штилевая погода, что приводит к деструкционным процессам в придонных водах и под воздействием повышения температур наблюдается снижение концентрации растворенного кислорода в придонном слое с 11 до 4-5 мг/л. Уменьшение концентрации растворенного кислорода в летний период отмечено и в работе [19]. При снижении концентрации растворенного кислорода в придонной воде замедляется процесс окисления растворенных форм $\mathrm{Fe} 2+$, что подтверждается отрицательной корреляцией между указанными показателями со значением коэффициента корреляции $-0,91$ при уровне значимости 0,01 . 
Таблица 3. Средние значения \pm стандартное отклонение концентрации растворенных форм соединений железа, меди, цинка, кадмия и свинца в поровой и придонной водах в весенний и летний периоды

Table 3. Mean values \pm standard deviation concentrations of dissolved forms of iron, copper, zinc, cadmium and lead in the pore and bottom waters in spring and summer

\begin{tabular}{|c|c|c|c|c|c|c|}
\hline \multirow{2}{*}{$\begin{array}{c}\text { Элемент, } \\
\text { мкг }{ }^{-1} \\
\text { Element, } \\
\mathrm{mkg} \cdot \mathrm{l}^{-1}\end{array}$} & \multirow{2}{*}{$\begin{array}{l}\text { Месяц } \\
\text { Month }\end{array}$} & \multirow{2}{*}{$\begin{array}{c}\text { Тип воды } \\
\text { Water type }\end{array}$} & \multicolumn{4}{|c|}{$\begin{array}{l}\text { Станция } \\
\text { Site } \\
\end{array}$} \\
\hline & & & S1 & $\mathrm{S} 3$ & S4 & S5 \\
\hline \multirow{4}{*}{$\mathrm{Fe}$} & \multirow{2}{*}{$\begin{array}{l}\text { Май } \\
\text { Мау }\end{array}$} & $\begin{array}{c}\text { Поровая } \\
\text { Pore }\end{array}$ & $404 \pm 40$ & $96 \pm 8$ & $294 \pm 18$ & $9540 \pm 668$ \\
\hline & & $\begin{array}{c}\text { Придонная } \\
\text { Bottom }\end{array}$ & $37 \pm 3$ & $163 \pm 15$ & $434 \pm 39$ & $557 \pm 56$ \\
\hline & \multirow{2}{*}{$\begin{array}{c}\text { Июль } \\
\text { July }\end{array}$} & $\begin{array}{c}\text { Поровая } \\
\text { Pore }\end{array}$ & $65 \pm 5$ & $16 \pm 1$ & $155 \pm 14$ & $79 \pm 6$ \\
\hline & & $\begin{array}{c}\text { Придонная } \\
\text { Bottom }\end{array}$ & $123 \pm 11$ & $830 \pm 72$ & $628 \pm 59$ & $1040 \pm 95$ \\
\hline \multirow{4}{*}{$\mathrm{Cu}$} & \multirow{2}{*}{$\begin{array}{l}\text { Май } \\
\text { Мау }\end{array}$} & $\begin{array}{c}\text { Поровая } \\
\text { Pore }\end{array}$ & $3,62 \pm 0,18$ & $5,21 \pm 0,21$ & $18,21 \pm 1,09$ & $4,98 \pm 0,19$ \\
\hline & & $\begin{array}{c}\text { Придонная } \\
\text { Bottom }\end{array}$ & $2,72 \pm 0,11$ & $3,71 \pm 0,18$ & $2,89 \pm 0,11$ & $1,49 \pm 0,09$ \\
\hline & \multirow{2}{*}{$\begin{array}{c}\text { Июль } \\
\text { July }\end{array}$} & $\begin{array}{c}\text { Поровая } \\
\text { Pore }\end{array}$ & $5,78 \pm 0,29$ & $3,54 \pm 0,18$ & $5,55 \pm 0,31$ & $1,82 \pm 0,07$ \\
\hline & & $\begin{array}{c}\text { Придонная } \\
\text { Bottom }\end{array}$ & $1,01 \pm 0,21$ & $1,42 \pm 0,06$ & $4,55 \pm 0,39$ & $0,24 \pm 0,01$ \\
\hline \multirow{4}{*}{$\mathrm{Zn}$} & \multirow{2}{*}{$\begin{array}{l}\text { Май } \\
\text { Мау }\end{array}$} & $\begin{array}{c}\text { Поровая } \\
\text { Pore }\end{array}$ & $8,14 \pm 0,49$ & $3,48 \pm 0,23$ & $15,12 \pm 0,61$ & $22,02 \pm 1,32$ \\
\hline & & $\begin{array}{c}\text { Придонная } \\
\text { Bottom }\end{array}$ & $2,81 \pm 0,17$ & $1,48 \pm 0,07$ & $5,93 \pm 0,29$ & $4,04 \pm 0,16$ \\
\hline & \multirow{2}{*}{$\begin{array}{c}\text { Июль } \\
\text { July }\end{array}$} & $\begin{array}{c}\text { Поровая } \\
\text { Pore }\end{array}$ & $1,96 \pm 0,06$ & $0,87 \pm 0,05$ & $1,97 \pm 0,08$ & $10,42 \pm 0,52$ \\
\hline & & $\begin{array}{c}\text { Придонная } \\
\text { Bottom }\end{array}$ & $0,71 \pm 0,03$ & $3,27 \pm 0,19$ & $1,99 \pm 0,11$ & $1,24 \pm 0,07$ \\
\hline \multirow{4}{*}{$\mathrm{Cd}$} & \multirow{2}{*}{$\begin{array}{l}\text { Май } \\
\text { Мау }\end{array}$} & $\begin{array}{l}\text { Поровая } \\
\text { Pore }\end{array}$ & $0,066 \pm 0,007$ & $0,056 \pm 0,006$ & $0,171 \pm 0,019$ & $0,181 \pm 0,016$ \\
\hline & & $\begin{array}{c}\text { Придонная } \\
\text { Bottom }\end{array}$ & $0,051 \pm 0,002$ & $0,069 \pm 0,003$ & $0,081 \pm 0,006$ & $0,052 \pm 0,004$ \\
\hline & \multirow{2}{*}{$\begin{array}{c}\text { Июль } \\
\text { July }\end{array}$} & $\begin{array}{c}\text { Поровая } \\
\text { Pore }\end{array}$ & $0,082 \pm 0,006$ & $0,018 \pm 0,001$ & $0,022 \pm 0,002$ & $0,058 \pm 0,004$ \\
\hline & & $\begin{array}{c}\text { Придонная } \\
\text { Bottom }\end{array}$ & $0,005 \pm 0,001$ & $0,053 \pm 0,005$ & $0,013 \pm 0,001$ & $0,001 \pm 0,0005$ \\
\hline \multirow{4}{*}{$\mathrm{Pb}$} & \multirow{2}{*}{$\begin{array}{l}\text { Май } \\
\text { Мау }\end{array}$} & $\begin{array}{c}\text { Поровая } \\
\text { Pore }\end{array}$ & $2,67 \pm 0,16$ & $1,58 \pm 0,11$ & $2,32 \pm 0,18$ & $1,37 \pm 0,11$ \\
\hline & & $\begin{array}{c}\text { Придонная } \\
\text { Bottom }\end{array}$ & $0,41 \pm 0,03$ & $0,31 \pm 0,02$ & $2,04 \pm 0,18$ & $0,32 \pm 0,02$ \\
\hline & \multirow{2}{*}{$\begin{array}{c}\text { Июль } \\
\text { July }\end{array}$} & $\begin{array}{c}\text { Поровая } \\
\text { Pore }\end{array}$ & $1,18 \pm 0,07$ & $0,79 \pm 0,06$ & $1,62 \pm 0,11$ & $1,68 \pm 0,15$ \\
\hline & & $\begin{array}{c}\text { Придонная } \\
\text { Bottom }\end{array}$ & $0,63 \pm 0,05$ & $0,65 \pm 0,05$ & $0,86 \pm 0,07$ & $0,59 \pm 0,05$ \\
\hline
\end{tabular}

Весной из ДО вместе с соединениями железа в поровый раствор переходили сорбированные на них соединения меди, цинка, кадмия и свинца. На границе поровый раствор - придонная вода возникает градиент концентрации растворенных форм железа, меди, цинка, кадмия и свинца. Это должно способствовать выходу растворенных форм металлов из порового раствора в придонную воду вследствие концентрационной диффузии, тем самым создавая угрозу вторичного загрязнения водного объекта ТМ. В летний период для растворенных форм меди, цинка и кадмия отмечена тенденция к уменьшению их содержания в придонной воде за исключением станции S4 для меди и S3 для цинка, где концентрация растворенных форм увеличивается. Что касается свинца, летом наблюдается увеличение растворимых форм в придонном слое Для объяснения процессов, происходящих на границе поровая вода - придонная вода в летний период, были произведены расчеты корреляционных зависимостей между концентрациями ТМ и содержанием растворенного кислорода в придонном слое водной системы. Связь между этими параметрами не установлена. На исследуемых станциях в летний период наблюдалось незначительное закисление придонного водного слоя. Величина $\mathrm{pH}$ изменялась от 7,2 до 6,8, корреляционная связь этого параметра с содержанием соединения ТМ не установлена. Не установлена и корреляция между концентрациями ТМ в придонной воде и поровом растворе в летний период, что, вероятно, указывает на изменение химического состава соединений ТМ в поровой воде под воздействием разных процессов.

Для оценки изменения поглотительной способности ДО прибрежной зоны восточной части Финского залива был выполнен расчет индивидуальных коэффициентов донной аккумуляции (КДА) металлов в весенний и летний периоды. КДА определяли по формуле 
КДА=Сдо/Сприд. вода,

где Сдо - концентрация загрязняющего соединения в ДО, мкг/кг; Сприд. вода - концентрация загрязняющего соединения в придонной воде, отобранной одновременно в этой же точке, мкг/л. Обычно с помощью КДА оценивается экологическая обстановка в водных системах, но при этом в расчетной формуле используется концентрация растворенных форм металлов поверхностного слоя воды и все критерии оценки степени химического загрязнения приводятся для поверхностных вод. В нашем случае при помощи параметра КДА мы оцениваем только изменение поглотительной способности ДО в условиях изменения физико-химических параметров на границе донные отложения - придонный водный слой в весеннелетний период.

На рис. 2 представлены индивидуальные значения КДА соединений железа, меди, цинка, кадмия и свинца в весенне-летний период.
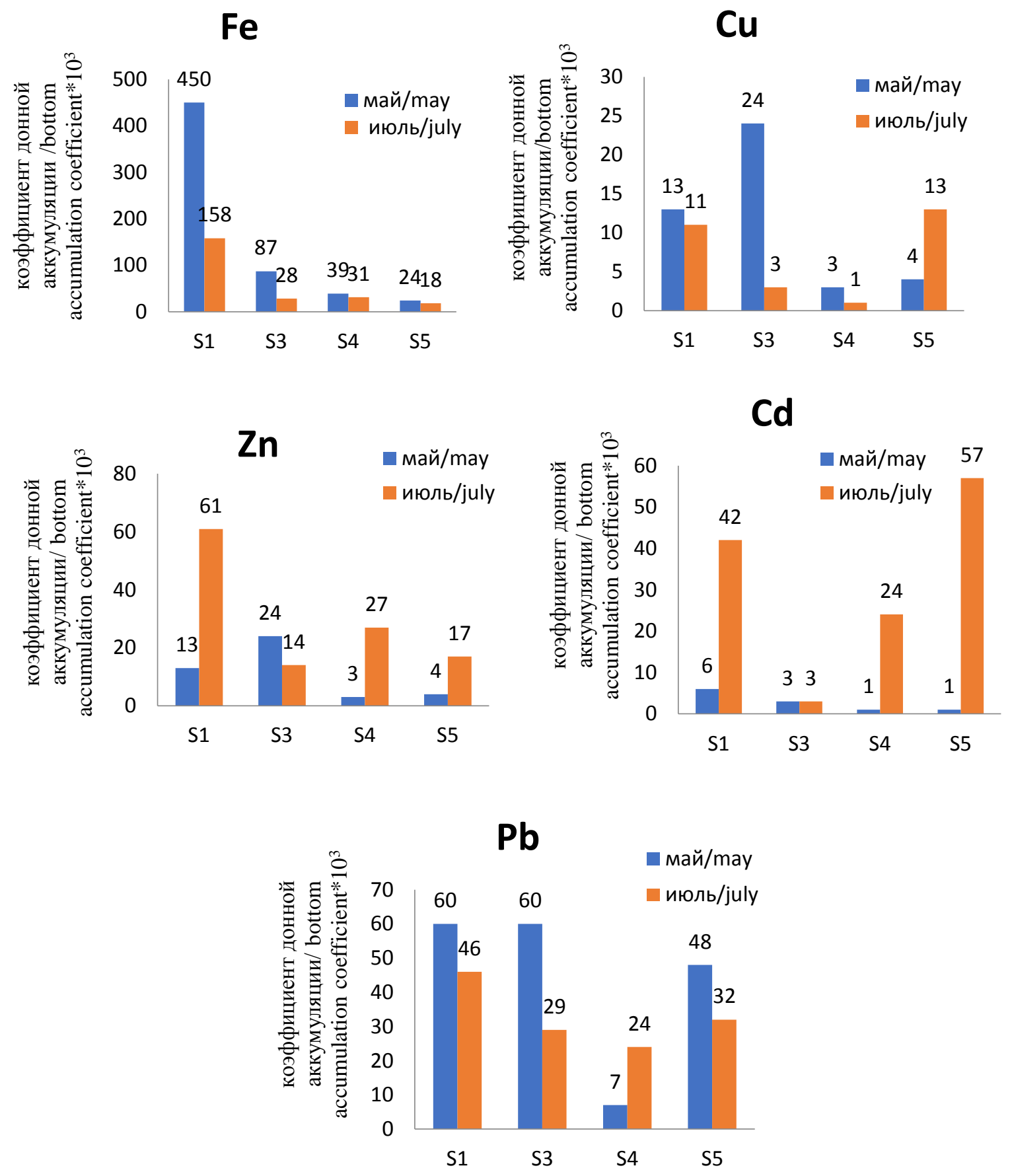

Pис. 2. КДА для $\mathrm{Fe}, \mathrm{Cu}, \mathrm{Zn}, \mathrm{Cd}, \mathrm{Pb}$ в весенний и летний период

Fig. 2. Bottom accumulation coefficient for $\mathrm{Fe}, \mathrm{Cu}, \mathrm{Zn}, \mathrm{Cd}, \mathrm{Pb}$ in spring and summer 
Из рис. 2 видно, что самыми высокими поглотительными свойствами по отношению к соединениям железа обладают ДО Приморска. В летний период по сравнению с весной величина КДА снижается в три раза на всех станциях за исключением Большой Ижоры. Для соединений меди снижение поглотительной способности ДО отмечено только для двух станций Дубки и Ломоносов, в ДО Приморска КДА не изменился, а поглотительная способность поверхностного слоя ДО Большой Ижоры увеличилась в 3 раза. Максимально увеличился в летний период КДА для соединений цинка (в 9 раз) на станции Ломоносов и в 24 и 57 раз для соединений кадмия на станциях Ломоносов и Большая Ижора. Для соединений свинца только на станции Ломоносов наблюдается увеличение поглотительной способности ДО в июле, на остальных станциях этот показатель снижается.

\section{Заключение}

ДО при определенных условиях могут быть источником загрязнения водоемов из-за перераспределения и миграции накопившихся загрязняющих веществ. Установлены закономерности образования и миграции растворенных форм металлов на границе донные отложения - вода в прибрежной зоне восточной части Финского залива в весенне-летний период. Определяющее влияние на эти процессы оказывают окислительно-восстановительные условия, сформированные в поверхностном слое ДО, сезонные изменения кислородного режима в придонном слое и температурный режим. Результаты натурных исследований показали, что в мае в прибрежных ДО восточной части Финского залива устанавливаются восстановительные условия, способствующие восстановлению

\section{СПИСОК ЛИТЕРАТУРЬ}

1. Climate change and human occupations in the Lake Daihai basin north-central China over the last 4500 years: ago-archeological perspective / L. Xu, Y. Liu, Q. Sun, J. Chen, P. Cheng, Z. Chen // Journal of Asian Earth Science. - 2017. - V. 138. - P. 367-377.

2. Gladyshev M.I., Gubelit Yu.I. Green tides: new consequences of the eutrophication of natural waters (invited review) // Contemporary Problems of Ecology. - 2019. - V. 12. - № 2. - P. 109-125.

3. Голубков С.М. Влияние климатических колебаний на структуру и функционирование экосистем континентальных водоемов // Сибирский экологический журнал. - 2021. - Т. 28. № 1. - C. 1-12.

4. Effects of climate change on streamflow extremes and implications for reservoir inflow in the United States / B.S. Naz, S.C. Kao, M. Ashfaq, H. Gao, D. Rastogi, S. Gangrade / Journal of Hydrology. - 2018. - V. 556. - P. 359-370.

5. Niinemets U., Karhu A., Notes P. Environmental feedbacks in temperate aquatic ecosystems under global change: why do we need to consider chemical stressors? // Regional Environmental Change. - 2017. - V. 17. - № 7. - P. 2079-2096.

6. Heavy metal contamination in sediments from typical lakes in the five geographic regions of China: distribution, bioavailability, and risk / W. Guo, S. Huo, B. Xi, J. Zhang, F. Wu // Ecological Engineering. - 2015. - V. 81. - P. 243-255.

7. Усманов И.А., Магай М.П Донные отложения как источник загрязнения природных вод // Экологический вестник Северного Кавказа. - 2020. - Т. 16. - № 1. - С. 73-77.

8. Cieslewicz J., Kobierski M., Cichosz M. Geochemical assessment of lake sediments in protected areas in Poland - a search for reference condition // Journal of Limnology. - 2018. - V. 77. № 1. - P. 35-45. гидроксидов железа, накопившихся на дне. При этом фиксируется рост концентраций соединений, в составе которых железо находятся в низшей степени окисления +2 в поровой воде. Поскольку концентрации этих соединений $\mathrm{Fe}^{2+}$ в поровой воде значительно выше, чем в придонной, возникает градиент концентраций на поверхности раздела фаз вода-дно, который приводит к диффузионному потоку этих соединений в придонные слои воды, при этом основной поток наблюдается весной в поровые воды, а летом в придонные воды. Уменьшение концентрации растворенного кислорода в июле позволяет растворенным формам железа преодолевать границу поровая вода придонная вода.

В процессе восстановления и растворения гидроксидов железа тяжелые металлы, локализованные на поверхности гидроксидов, мобилизуются и мигрируют вместе с растворенными формами соединений $\mathrm{Fe}^{2+}$ в поровые воды. В результате в мае прибрежные донные осадки служат источником поступления растворенных форм $\mathrm{Fe}, \mathrm{Cu}, \mathrm{Zn}, \mathrm{Cd}, \mathrm{Pb}$ из ДО в придонные воды. В июле загрязненность поровых и придонных вод изученными металлами снижается. Таким образом, на основании проведенных исследований можно сделать вывод о достаточно высокой изменчивости содержания растворимых форм исследуемых металлов в верхнем придонном слое прибрежной зоны Финского залива в весенне-летний период, которые активно вовлекаются в процесс массообмена на границе донные отложения - поровая вода - придонная вода.

Работа выполнена при поддержке Минобрнауки России (nо теме АAАA-A19-119020190122-6).

9. Мониторинг Финского залива Балтийского моря: влияние антропогенных факторов на биогеохимические процессы в прибрежной зоне / Ю.М. Поляк, Ю.И. Губелит, Т.Д. Шигаева, В.А. Кудрявцева, Л.Г. Бакина, Г. Дембска, Г. ПазиковскаСапота // Проблемы экологического мониторинга и моделирования экосистем. - 2018. - Т. 29. - № 2. - С. 99-117.

10. Can the "Green Tides» affect the metal distribution in the coastal sediments? A case study in the Eastern Gulf of Finland, Baltic Sea / Y.I. Gubelit, Y.M. Polyak, T.D. Shigaeva, L.G. Bakina, V.A. Kudryavtseva // Contemporary Problems of Ecology. 2020. - V. 13. - № 2. - P. 113-126.

11. Кудрявцева В.А., Шигаева Т.Д., Конаков В.Г. Влияние свойств поверхностного слоя донных отложений прибрежной зоны восточной части Финского залива на содержание тяжелых металл // Вода: химия и экология. - 2016. - № 11. - С. 16-23.

12. Manganese reduction by microbes from oxic regions of lake Vanda (Antarctica) water column / B.J. Bratina, B.S. Stevenson, W.J. Green, T.M. Schmidt // Applied and Environmental Microbiology. - 1998. - V. 64. - № 10. - P. 3791-3797.

13. Линник П.Н., Жежеря В.А., Жежеря Т.П. Миграция химических элементов в системе «донные отложения - вода» поверхностных водоемов при воздействии различных факторов среды // Экологическая химия. - 2016. - Т. 25. - № 4. - С. 222-240.

14. Папина Т.С. Транспорт и особенности распределения тяжелых металлов в ряду: вода - взвешенное вещество - донные отложения речных экосистем. Аналитический обзор. Сер. Экология. Вып. 62. - Новосибирск: ГПНТБ, 2001. - 58 с.

15. Коломийцев И.В., Корженский Б.И., Толкачев Г.Ю. Роль поровых растворов отложений водоемов в процессах самоочищения и вторичного загрязнения водной среды // Экологические системы и приборы. - 2019. - № 8. - С. 16-25. 
16. Липатникова О.А., Лубкова Т.Н., Коробова Н.А. Формы нахождения микроэлементов в воде и донных отложениях Пироговского водохранилища // Вестник Московского университета. Серия 4. Геология. - 2020. - № 4. - С. 59-68.

17. Брезгунов В.С. Содержание $\mathrm{Mn}$ и $\mathrm{Pb}$ в поровых водах среднего и южного Каспия в связи с оценкой геохимического состояния Каспийского моря // Вода: химия и экология. - 2014. № 7 (73). - С. 24-28.

18. Шигаева Т.Д., Поляк Ю.М., Кудрявцева В.А. Окислительновосстановительный потенциал как показатель состояния объ- ектов окружающей среды // Биосфера. - 2020. - Т. 12. - № 3. C. $111-124$

19. Степанова И.Э. Качество воды Рыбинского водохранилища: режим растворенного кислорода // Водное хозяйство России. -2016 . - № 5. - С. 23-34.

20. Методика «Критерии оценки экологической обстановки территорий для выявления зон чрезвычайной экологической ситуации и зон экологических бедствий». - М.: Министерство природных ресурсов РФ, 1992. - 63 с.

Поступила 23.12.2021 2.

\section{Информация об авторах}

Кудрявцева В.А., кандидат химических наук, заведующая лабораторией изучения миграционных форм экотоксикантов в окружающей среде Санкт-Петербургского научно-исследовательского центра экологической безопасности Российской академии наук - обособленного структурного подразделения Санкт-Петербургского Федерального исследовательского центра Российской академии наук.

Шигаева T.Д., кандидат химических наук, старший научный сотрудник лаборатории изучения миграционных форм экотоксикантов в окружающей среде Санкт-Петербургского научно-исследовательского центра экологической безопасности Российской академии наук - обособленного структурного подразделения СанктПетербургского Федерального исследовательского центра Российской академии наук.

Панкратова Н.М., инженер по разработке сенсоров, Sentec AG. 
UDC 550.424.4

\title{
FEATURES OF MIGRATION OF HEAVY METALS IN THE SYSTEM «BOTTOM WATER - PORE WATER - SURFACE LAYER OF BOTTOM SEDIMENTS» OF THE COASTAL ZONE IN THE EASTERN PART OF THE GULF OF FINLAND
}

\author{
Valentina A. Kudryavtseva ${ }^{1}$, \\ valenkud@yandex.ru \\ Tatyana D. Shigaeva ${ }^{1}$ \\ t.sh54@mail.ru \\ Nadezda M. Pankratova², \\ nadja.pan@gmail.com \\ 1 Scientific Research Centre for Ecological Safety of the Russian Academy of Sciences, \\ 18, Korpusnaya street, St. Petersburg, 197110, Russia. \\ 1 Sentec $A G$, \\ 39, Ringstrasse, Therwil, 4106, Switzerland
}

The relevance of the research is caused by the need to study the secondary pollution of the aquatic environment with metals in springsummer, when various biogeochemical processes are activated that affect the change in the physicochemical state of the surface layer of bottom sediments.

The aim of the research is to study the patterns of formation and migration of soluble forms of metals in the system «bottom sediments pore water - bottom water» depending on the spring-summer season and conditions of the coastal zone in the eastern part of the Gulf of Finland.

Objects: samples of the surface layer of bottom sediments, pore and bottom water from five stations in the coastal zone in the eastern part of the Gulf of Finland.

Methods: potentiometric method for determining $\mathrm{pH}$ and $\mathrm{Eh}$ in sediments and bottom water. The bulk concentrations of $\mathrm{Fe}, \mathrm{Zn}, \mathrm{Cd}, \mathrm{Pb}, \mathrm{Cu}$ in bottom sediments were determined by inductively coupled plasma mass spectrometry (ICP-MS). Concentrations of dissolved forms of metals ( $\mathrm{Fe}, \mathrm{Cu}, \mathrm{Cd}, \mathrm{Zn}, \mathrm{Pb})$ in the pore, bottom waters were determined by inductively coupled plasma mass spectrometry on an Agilent 7700x instrument (Agilent Technologies).

Results. The authors have established the regularities of the formation and migration of soluble forms of metals at the «bottom sedimentwater» boundary in the coastal zone of the eastern part of the Gulf of Finland, depending on temperature changes, oxygen regime in bottom waters and redox processes formed in the surface layer of bottom sediments. It is shown, that at the end of the spring season, reducing conditions are established in the bottom sediments of the eastern part of the Gulf of Finland, contributing to the reduction of iron hydroxides accumulated on the bottom. As a result, there is a flow of dissolved forms of $\mathrm{Fe}, \mathrm{Cu}, \mathrm{Zn}, \mathrm{Cd}, \mathrm{Pb}$ into the pore and bottom layers of water. In July, the pollution of pore and bottom waters with all studied metals decreases.

\section{Key words:}

Bottom sediments, pore waters, bottom waters, heavy metals, Gulf of Finland.

The research was supported by the Ministry of Education and Science of the Russian Federation (subject AAAA-A19-119020190122-6).

\section{REFERENCE}

1. Xu L., Liu Y., Sun Q., Chen J., Cheng,P., Chen Z. Climate change and human occupations in the Lake Daihai basin, north-central China over the last 4500 years: a geo-archeological perspective. Journal of Asian Earth Science, 2017, vol. 138, pp. 367-377.

2. Gladyshev M.I., Gubelit Yu.I. Green tides: new consequences of the eutrophication of natural waters (invited review). Contemporary Problems of Ecology, 2019, vol. 12, no. 2, pp. 109-125.

3. Golubkov S.M. The influence of climatic fluctuations on the structure and functioning of ecosystems of continental water bodies. Siberian Journal of Ecology, 2021, vol. 28, no. 1, pp. 1-12. In Rus.

4. Naz B.S., Kao S.C., Ashfaq M., Gao H., Rastogi D., Gangrade S. Effects of climate change on streamflow extremes and implications for reservoir inflow in the United States. Journal of Hydrology, 2018, vol. 556, pp. 359-370.

5. Niinemets U., Kahru A., Noges P. Environmental feedbacks in temperate aquatic ecosystems under global change: why do we need to consider chemical stressors? Regional Environmental Change, 2017, vol. 17, no. 7, pp. 2079-2096.

6. Guo W., Huo S., Xi B., Zhang J., Wu F. Heavy metal contamination in sediments from typical lakes in the five geographic regions of China: distribution, bioavailability, and risk. Ecological Engineering, 2015, vol. 81, pp. 243-255.

7. Usmanov I.A., Magay M.P Bottom sediment as a natural water. The North Caucasus Ecological Herald, 2020, vol. 16, no. 1, pp. 73-77. In Rus.

8. Cieslewicz J., Kobierski M., Cichosz M. Geochemical assessment of lake sediments in protected areas in Poland - a search for reference condition. Journal of Limnology, 2018, vol. 77, no. 1, pp. 35-45.

9. Polyak Y.M., Gubelit Y.I, Shigaeva T.D., Kudryavtseva V.A., Bakina L.G., Dembska G. Pazikowska-Sapota G. Monitoring of the Gulf of Finland, Baltic Sea: anthropogenic pressure on biogeochemical, processes in the coastal zone. Problems of Ecological Monitoring and Ecosystem Modelling, 2018, vol. 29, no. 2, pp. 99-117. In Rus.

10. Gubelit Y.I., Polyak Y.M., Shigaeva T.D., Bakina L.G., Kudryavtseva V.A. Can the «Green Tides» affect the metal distribution in the coastal sediments? A case study in the Eastern Gulf of Finland, Baltic Sea. Contemporary Problems of Ecology, 2020, vol. 13, no. 2, pp. 113-126.

11. Kudryavtseva V.A., Shigaeva T.D., Konakov V.G. Influence of properties of a superficial layer of ground sediments of a coastal zone of east part of Gulf of Finland on a content of heavy metals. Water: Chemistry and Ecology, 2016, no. 11, pp. 16-23. In Rus. 
12. Bratina B.J., Stevenson B.S., Green W.J., Schmidt T.M. Manganese reduction by microbes from oxic regions of lake Vanda (Antarctica) water column. Applied and Environmental Microbiology, 1998, vol. 64, no. 10, pp. 3791-3797.

13. Linnik P.N., Zhezherya V.A., Zhezherya T.P. Migration of chemical elements in the «bottom sediments - water» system of surface water bodies influenced by different environmental factors. Ecological Chemistry, 2016, vol. 25, no. 4, pp. 222-240. In Rus.

14. Papina T.S. Transport $i$ osobennosti raspredeleniya tyazhelyh metallov $v$ ryadu: voda -vzveshennoe veshchestvo - donnye otlozheniya rechnykh ekosistem. Analiticheskiy obzor. Ser. Ekologiya (62) [Transport and distribution features of heavy metals in the series: water - suspended matter - bottom sediments of river ecosystems. Analytical review. Ser. Ecology (62)]. Novosibirsk, GPNTB Publ., 2001. $58 \mathrm{p}$

15. Kolomiytsev N.V., Korzhenevskiy B.I., Tolkachev G.Y. The role of pore solutions of sediments in the processes of self-purification and secondary pollution of aquatic environment. Ecological Systems and Devices, 2019, no. 8, pp. 16-25. In Rus.

16. Lipatnikova O.A., Lubkova T.N., Korobova N.A. Trace element speciation in water and bottom sediments of the Pirogov Water
Reservoir. Vestnik Moskovskogo Universiteta. Seriya 4: Geologiya, 2020, no. 4, pp. 59-68. In Rus.

17. Brezgunov B.S. Content of $\mathrm{Mn}$ and $\mathrm{Pb}$ in pore waters of the Middle and Southern Caspian in connection with the evaluation of geochemical status of the Caspian Sea. Water: Chemistry and Ecology, 2014, no. 7 (73), pp. 24-28. In Rus.

18. Shigaeva T.D., Polyak Yu.M., Kudryavtseva V.A. The redox potential as an index of the state of environmental entities. Biosfera, 2020, vol. 12, no. 3, pp. 111-124. In Rus.

19. Stepanova I.E. Kachestvo vody Rybinskogo vodokhranilishcha: rezhim rastvorennogo kisloroda [Rybinsk reservoir water quality: dissolved oxygen regime]. Vodnoe khozyaistvo Rossii, 2016, no. 5, pp. 23-34.

20. Metodika «Kriterii otsenki ekologicheskoy obstanovki territory dlya vyyavleniya zon chrezvychaynoy ekologicheskoy situatsii $i$ zon ekologicheskikh bedstvy» [Methodology «Criteria for assessing the ecological situation of territories for identifying zones of ecological emergency and zones of ecological disasters»]. Moscow, Ministry of Natural Resources of the Russian Federation, 1992. $63 \mathrm{p}$.

Received: 23 December 2021.

\section{Information about the authors}

Valentina A. Kudryavtseva, Cand. Sc., head of laboratory, Scientific Research Centre for Ecological Safety of the Russian Academy of Sciences.

Tatyana D. Shigaeva, Cand. Sc., senior scientist, Scientific Research Centre for Ecological Safety of the Russian Academy of Sciences.

Nadezda M. Pankratova, sensor development engineer, Sentec AG. 